\title{
Sertraline was effective and well tolerated for generalised social phobia
}

Van Ameringen MA, Lane RM, Walker JR, et al. Sertraline treatment of generalized social phobia: a 20-week, double-blind, placebo-controlled study. Am J Psychiatry 2001 Feb;158:275-81.

QUESTION: In patients with generalised social phobia, how safe and effective is sertraline?

\section{Design}

Randomised (unclear allocation concealment*), blinded \{clinicians, patients, and outcome assessors*\}†, with 20 weeks of follow up.

\section{Setting}

10 outpatient anxiety clinics in Canada.

\section{Patients}

204 patients who were $18-60$ years of age (mean age 36 y, $56 \%$ men), met $D S M-I V$ criteria for generalised social phobia lasting $\geqslant 1$ year, and had a Clinical Global Impression (CGI) severity rating of $\leqslant 4$. Exclusion criteria were uncontrolled illness precluding sertraline use, concomitant use of psychotropic or anti-anxiety medication, neuroleptics, serotonergic antidepressants, benzodiazepines, or $B$-blockers or clonidine; another primary axis I disorder or met criteria for agoraphobia, or panic, obsessive compulsive, eating, or body dysmorphic disorders, or substance abuse in the previous 6 months; pregnancy, lactation, or potential for pregnancy; or a serious life event in the previous 3 months. Efficacy data for 203 patients $(99.5 \%$ ) (received $\geqslant 1$ dose of double blind medication and $\geqslant 1$ post-baseline efficacy evaluation) were available.

\section{Intervention}

Patients were allocated to sertraline, $50 \mathrm{mg}$ /day, which could be increased to a maximum dose of $200 \mathrm{mg}$ /day by week $10(\mathrm{n}=135)$ or placebo $(\mathrm{n}=69)$.

\section{Main outcome measures}

CGI improvement item, change from baseline to endpoint on the patient rated 5 item social phobia subscale of the Marks Fear Questionnaire, and change on the physician rated Brief Social Phobia Scale.

\section{Main results}

Analysis was by intention to treat. More patients who received sertraline than placebo were much or very much improved on the CGI improvement item $(\mathrm{p}<0.01)$ (table). Sertraline group patients also had greater reductions than placebo group patients on the Marks Fear Questionnaire $(33 \%$ v 19\%, p < 0.01$)$ and on the Brief Social Phobia Scale (34\% v 19\%, p<0.01) (table). Nausea, insomnia, dyspepsia, flu syndrome, and delayed ejaculation in men were more common in sertraline recipients than placebo recipients $(p \leqslant 0.04)$. $7 \%$ of patients in both groups had severe adverse effects.

\section{Conclusion}

In patients with generalised social phobia, sertraline was effective and well tolerated.

*See glossary.

$\dagger$ Information provided by author.

\section{COMMENTARY}

The study by Van Ameringen et al is yet another well designed and well executed study confirming the efficacy, tolerability, and safety of a selective serotonin reuptake inhibitor (SSRI) in the treatment of generalised social phobia. Because of this and similar studies, SSRIs have come to be considered first line treatment for this condition. Although the study results are valid, clinicians are left with questions about their clinical relevance.

The inclusion criteria are clearly described, but clinicians lack data to judge the inclusion process and to compare the patients with their own. A flowchart, starting from the number of people reacting to the recruitment through newspaper advertisements, media reports, and clinician referrals, and indicating reasons for exclusion or refusal to participate, would have been useful. The high proportion of patients with avoidant personality disorder in this study is similar to real clinical practice, but the low presence of major depressive episode $(2 \%)$ and the exclusion of patients with panic disorder, agoraphobia, or substance abuse (conditions with high comorbidity with generalised social phobia) are problematic in this respect.

Other remaining questions concern the effect of medication discontinuation and long term treatment, and the usefulness of other combined or sequential treatment modalities (pharmacological or cognitive behavioural) in patients refractory to treatment with SSRIs.

Finally, patient preference needs to be considered in judging the relevance of these results. Patient refusal was the main source of pre-treatment attrition in a study on panic disorder. ${ }^{1}$ Results of treatment outcome studies are limited not only to people who meet criteria, but also to those who are willing to start a medication treatment. Some patients presenting in primary care or psychiatric clinics may not accept pharmacological treatment, although it has been shown to be effective.

Studies addressing these and other clinical questions are eagerly awaited in the field of treatment of anxiety disorders, particularly in general and social phobia.

Guido Pieters, MD

Universitair Gezondheidscentrum

Leuven, Belgium

1 Hofmann SG, Barlow DH, Papp LA, et al. Pretreatment attrition in a comparative treatment outcome study on panic disorder. Am J Psychiatry 1998;155:43-7.
Sertraline v placebo for generalised social phobia at 20 weeks

\begin{tabular}{lllll}
\hline Outcomes & Sertraline & Placebo & RBI (95\% CI) & NNT (CI) \\
\hline Much or very much improved on the Clinical Global Impression improvement item & $53 \%$ & $29 \%$ & $83 \%$ (25 to 178) & 5 (3 to 11) \\
\hline Mean decrease from baseline on the Marks Fear Questionnaire & & & Difference (CI) \\
\hline Mean decrease from baseline on the Brief Social Phobia Scale & 7.53 & 2.34 & 5.19 (2.70 to 7.69$)$ \\
\hline
\end{tabular}

$\ddagger$ Abbreviations defined in glossary; RBI, NNT, and $\mathrm{Cl}$ calculated from data in article.
Source of funding: Pfizer Inc.

For correspondence: Dr MA Van Ameringen, Anxiety Disorders Clinic, McMaster University Medical Centre, Hamilton, Ontario L8N 3Z5, Canada. Fax +19055212628 